\title{
Surfactant Therapy in Severe Meconium Aspiration Syndrome
}

Sang Lak Lee, M.D., Ph.D., and Chun Soo Kim, M.D., Ph.D.

Department of Pediatrics, Keimyung University School of Medicine, Daegu, Korea

\section{중증 태변 흡인 증후군에서 폐표면 활성제 치료}

계명대학교 의과대학 소아과학교실

이상락·김천수

\section{ABSTRACT}

Received: 12 August 2013

Accepted: 13 August 2013

Meconium is a strong inactivator of pulmonary surfactant. The deficiency of surfactant or surfactant dysfunction may contribute to respiratory failure in a wide group of disorders, including meconium aspiration syndrome (MAS). We reviewed the effect of pulmonary surfactant therapy for severe MAS in ours as well as other countries. In general, surfactant therapy improves pulmonary oxygenation (oxygenation index or arterial/alveolar oxygen tension) and reduces the requirement for ventilation, and oxygen supplementation or hospitalization time. However, its effects on mortality and pulmonary or extrapulmonary complications are variable. In Korean studies, outborn infants are five times more common than inborn infants; therefore, the initial hospital care at delivery including adequate tracheal suctioning is important to improve the outcome of patients with severe MAS. To confirm the effect of surfactant therapy in MAS, additional well-designed, multicenter, randomized, controlled trials are needed. In addition, determining the optimal type of surfactant therapy (bolus, lavage, or combined) and the appropriate dose and duration of therapy is important.

Key Words: Meconium aspiration syndrome, Pulmonary surfactant

\section{서론}

1959년 Avery와 Mead릐 의 폐 세척액 연구에서 신생아 호흡곤란 증후군(respiratory distress syndrome, RDS)이 폐포 표면장력을 낮추어주는 surfactant (SF)의 부족에 의한다고 발표된 이래 폐표면 활성제를 이용한 보충요법(surfactant replacement therapy, SRT)에 대한 연구가 활발히 지속되었다. 1980년에 이르러서는 Fujiwara 등에 에 의해 실제 임상에서 적용되기 시작 하여 국내외로 주로 폐 미성숙으로 인한 호흡곤란 증후군의 증상이 있는 미숙아의 치료에 사

Copyright(c)

By Korean Society of Neonatology. All right reserved. 
용되어서 치료방법이 확립되었다.

근래 $\mathrm{SRT}$ 의 영역이 확대되고 있으며 RDS 이외에도 $\mathrm{SF}$ 의 비 활성화가 동반되는 질환으로 태변 흡인 증후군 $(\mathrm{MAS})^{3,4)}$, 급성 폐손상(acute lung injury)과 급성 호흡곤란증(acute respiratory distress syndrome, $\mathrm{ARDS})^{5)}$, 대량 폐출혈 ${ }^{6)}, \mathrm{B}$ 군 사슬알균 폐렴 ${ }^{7)}$, respiratory syncytial 바이러스 모세기관지염8), 천식 ${ }^{9)}$, 낭성 섬유 증 $^{10)}$, 선천성 가로막 탈출증 ${ }^{11)}$ 등에서 이용되고 있다.

특히 높은 합병증과 후유증이 동반되고 예후가 불량한 중증 $\mathrm{MAS}$ 에서의 이용이 외국에서는 많이 보고되고 있고 저자도 2003 년 소아과학회발표에서 폐기능 호전의 유용성이 있는 것으로 보 고 $^{12}$ 하였다. 이에 태변의 폐표면 활성제에 대한 작용 및 폐 손상과 별다른 치료법이 없는 중증 MAS에서 국내외의 SRT 효과를 문헌 적 고찰해보고자 한다.

\section{태변에 의한 폐표면 활성제 억제 작용}

태변은 $\mathrm{SF}$ 의 표면 장력 감소 기능을 억제 하여 표면 장력을 증 가시키는 것으로 Chen 등 ${ }^{13)}$ 의 연구에서 밝혀졌으며, 이는 Moses 등 $^{14)}$ 의 연구에서 6,500 배로 희석한 태변 용액에서도 의미있게 표 면 장력의 감소가 억제된다고 하였으며 이는 태변의 농도가 높아 질수록 억제 효과가 의미있게 높다고 하였다. Bae 등 ${ }^{15)}$ 도 태변 용 액 농도에 따른 표면 장력의 감소 억제의 유사한 결과를 보고하면 서 동시에 고농도의 인공 폐표면 활성제 혼합으로 태변에 의한 표 면 장력 증가를 의미있게 감소 할 수 있다고 하여 MAS에서의 폐 표면 활성제 치료의 근거를 제시해주고 있다(Fig. 1).

Cleary 등 ${ }^{16)}$ 은 태변이 폐표면 활성제 단백(surfactant protein,

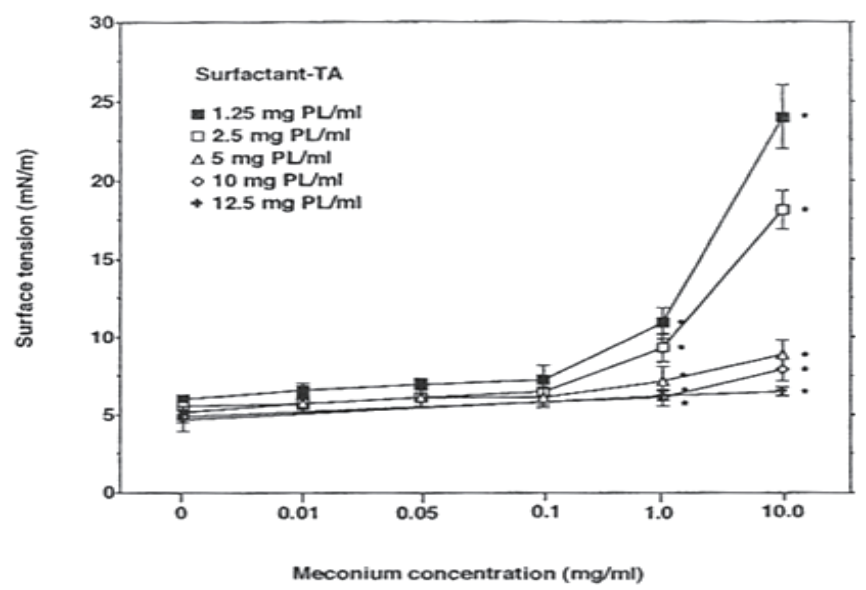

Fig. 1. The effects of various concentrations of surfactantmeconium mixtures on dynamic minimum surface tension $(\mathrm{mN} / \mathrm{m}) ;{ }^{*} P<0.01$ vs. $0 \mathrm{mg} / \mathrm{mL}$ meconium concentration. From Bae CW, et al. Pediatr Res 1998;44:187-91[15].
$\mathrm{SP}) \mathrm{A}$ 와 B 수치를 의미있게 감소시키며 이 효과는 48시간 지속된 다고 하였으며, Sun 등 ${ }^{17)}$ 은 태변내 존재하는 단백질, 빌리루빈, 유 리 지방산, triglyceride 와 콜레스테롤이 $\mathrm{SF}$ 의 작용을 억제한다고 하였다. 이외에도 MAS 환아의 폐액내 존재하는 알부민을 포함한 단백질과 인지질 및 폐부종액이 폐표면 활성제의 억제 효과를 나 타낸다 ${ }^{18)}$. 태변은 폐 염증세포를 자극하여 염증성 사이토카인들즉 interleukin (IL)-1 $\alpha, \mathrm{IL}-6, \mathrm{IL}-8$, tumor necrosis factor (TNF)$\alpha$, interferon $-\gamma$, granulocyte-macrophage colony-stimulating factor (GM-CSF) 등-을 유리시켜 폐 손상과 폐표면 활성제 불활 성화를 야기하는 것으로 알려져 있다 ${ }^{19-21)}$. 또한 태변 자체와 태변 에 함유된 담즙산이 phospholipase A2 (PLA2) 활성도를 증가시켜 염증성 사이토카인을 분비시켜 폐표면 활성제의 불활성화를 야 기하는 것으로 보고되었다 ${ }^{22,23)}$

\section{MAS에 대한 폐표면 활성제 치료: 국제 연구}

동물의 MAS에 대한 폐표면 활성제 투여를 제외한 인체에 대 한 연구는 1991년 Auten 등 ${ }^{3)}$ 이 7명에 투여하여 투여후 6시간 까 지 산소화(동맥혈-폐포 산소화비, 산소화 지수)의 개선을 나타 내며 이는 특히 반복 투여시 더 효과적이라고 하였으며, 1993년 Khammash 등 ${ }^{24)}$ 이 20명에 투여하여 평균 산소화 지수가 투여 1-3 시간 전 $36 \pm 12$ 에서 투여 $1-3$ 시간 후 $24 \pm 14$ 로 의미있게 개선된 다고 $(P<0.001)$ 하였으나 두 보고 모두 대조군이 없는 한계점이 있 었다. 대조군을 포함한 해외 연구를 살펴보면 Findlay 등 ${ }^{25)}$ 은 보충 요법(bolus therapy)을 시행한 20명과 대조군 20명의 만삭아를 비 교하여 투여군에서 대조군보다 산소화 지수(oxygenation index, $\mathrm{OI})$ 및 폐포/동맥혈 산소분압 비(a/ $\mathrm{A} \mathrm{PO}_{2}$ ratio)가 의미있게 호전 되었으며 $(P<0.05)$, 공기 누출빈도( $20 \% \mathrm{vs} 0 \%, P<0.05)$, 체외막 산 소기(extracorporeal membrane oxygenation, $\mathrm{ECMO}$ ) 치료 환아수 (30\% vs $5 \%, P<0.05)$, 인공환기기 투여일수(10.8 \pm 1.3 vs $7.7 \pm 0.7$,

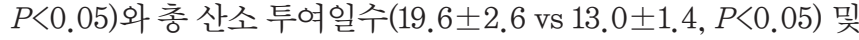

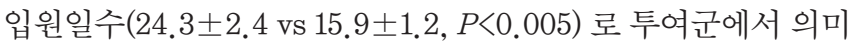
있게 낮고 짧았다고 하였다. 그러나 신생아 사망례는 양쪽 모두 없어 차이가 없었다.

Lam 등 ${ }^{26)}$ 은 세정요법(lavage therapy)을 시행한 6명과 대조 군 6 명의 만삭아를 비교하여 투여군에서 대조군보다 세정군에 서 투여 2시간 후부터 OI와 $\mathrm{a} / \mathrm{A} \mathrm{PO}_{2}$ 가 의미 있게 호전되었으며 $(P<0.05)$, 인공환기기 투여일수( $5.5 \pm 2.5$ vs $2.3 \pm 0.2, P<0.05)$ 와

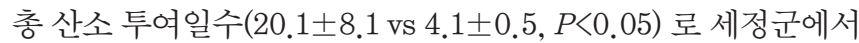
의미있게 짧았다고 하였다. 그런데 신생아 폐동맥 고혈압 지속증 (persistent pulmonary hypertension of the newborn, PPHN)(100\% vs $33 \%)$ 과 공기누출( $67 \%$ vs $0 \%)$ 및 사망률(33\% vs 0\%)은 모두 세 
정군에서 낮았으나 환아수가 적어서인지 의미있지는 않았다.

Wiswell 등 ${ }^{27}$ 은 세정요법을 시행한 15 명과 대조군 7 명의 준만삭 아를 비교하여 평균 인공 환기기에서 짧은 투여일수(9.9 vs 6.3)와 빠른 OI 호전을 세정군에서 보였다고 하였다. 그런데 PPHN $(6.7 \%$ vs $14.3 \%)$ 과 공기누출(6.7\% vs 0\%) 및 사망률(0\% vs 0\%) 은 별 차이 가 없었다.

중국 다기관 연구 ${ }^{28)}$ 에서는 보충요법을 시행한 31 명과 대조군 30 명의 준만삭아를 비교하여 투여군에서 24시간 후 낮은 평균 OI (8.1 vs 10.9)와 투여전 보다 많은 $\mathrm{a} / \mathrm{APO}_{2} 100 \%$ 증가( $83 \% \mathrm{vs} 48 \%$, $P<0.01)$ 을 나타낸다고 하였지만, 인공환기 기간과 공기 누출빈도 에서는 차이가 없었다고 하였다.

Dargaville 등 ${ }^{29}$ 은 세정요법을 시행한 30 명과 대조군 35 명의 비 교하여 평균 인공 환기기 투여일수(5.5 vs 6.0), 산소 투여일수(14 vs 14$)$, 기흥 빈도(23\% vs $23 \%)$, 고빈도 인공환기기(HFOV)와 흡입 일산화질소(iNO) 사용기간 등은 유사하였고, 세정군에서 사망하 거나 ECMO 치료 환아 비율이 $10 \%$ vs $31 \%$ 로 상대 위험도 0.24(95\% 신뢰 구간: 0.06-0.97)로 유의하게 낮았으며 평균 기도압(MAP)이 더 빨리 감소한다고 하였다.

Segal 등 ${ }^{30)}$ 은 세정요법을 시행한 38명과 대조군 31 명의 비교하 여 평균 인공 환기기 투여 일수(10.2 vs 8.1), 공기 누출 빈도(5.3\% vs $0 \%)$ 는 유사하였고, 사망한 환아는 양쪽 없었다. 이렇게 다양 한 결과가 나오는 것은 투여 방법과 투여 SF약제 및 투여 시기 등 의 차이에서 기인했을 수 있을 것이라 생각된다. 이들의 연구를 요약하면 Table 1과 같으며, 이들을 포함한 가장 광범위한 메타 분 석 연구는 Luo 등 ${ }^{31}$ 이 8개의 연구를 대상으로 시행하여 $\mathrm{SF}$ 투여 군 257 명과 대조군 255 명을 분석하여 투여군에서 대조군보다 의 미있게 OI 개선(평균차, mean difference, $\mathrm{MD}=-2.59 ; 95 \%$ 신뢰구 간: $-4.33,-0.86, P\langle 0.005), \mathrm{a} / \mathrm{A} \mathrm{PO}_{2}(\mathrm{MD}=0.05 ; 95 \%$ 신뢰 구간: $0.05,0.06, P\langle 0.0001)$, 짧은 입원 기간 $(\mathrm{MD}=-4.94 ; 95 \%$ 신뢰 구 간: $-7.44,-2.44, P=0.0001$ )과 감소된 사망률 (위험도 $=0.47 ; 95 \%$ 신뢰 구간: $0.24,0.93, P<0.05)$ 을 보였다고 하였다. 그러나 대상 환아의 과반이 중국에서 시행한 연구라는 단점이 있었다.

\section{국내 연구}

$\mathrm{RDS}$ 를 제외한 질환에서 폐표면 활성제 투여에 대한 국내 연구 를 살펴보면 1999년 저자 등 ${ }^{22)}$ 이 대량 폐출혈 환자에 주입후 빠른 OI의 개선과 양호한 예후를 첫 증례 보고 하였다. Shon 등 ${ }^{33)}$ 은 인 공환기기 치료가 필요하였던 중증 $\mathrm{MAS}$ 군 15 명과 심한 폐질환군 6 명의 준만삭아와 만삭아에 투여하여 양군 모두 유의하게 빠른 흡 입 산소농도와 OI 감소를 확인하였다. Choi 등 ${ }^{34}$ 은 ARDS 환아 1 명 에게 저용량 스테로이드와 겸용하여 빠른 폐기능 개선을 보고하 였고, Park 등 다)은 산모 혈액 흡인에 의한 ARDS 환아 1 명에게 투 여하여 지속적인 OI 감소와 흥부 방사선사진 호전을 얻었다. Park 등 ${ }^{36)}$ 은 중증 양수 흡인성 폐렴 환아 28 명에게 보충요법을 시행하 여 빠른 흡입 산소농도와 OI 감소 및 후유증 감소를 보고하였으 며, Choi 등 ${ }^{377}$ 은 심한 MAS 환아 8 명을 보충요법 5 명과 세척요법 3 명을 비교하여 두 군간에 중증도는 유의한 차이가 없다고 하였다. 그러나 앞의 보고들은 모두 폐표면 활성제 투여를 않은 대조군이 없는 한계점이 있었다. 대조군을 포함한 연구는 저자 들이 2003 년 제 53 차 대한소아과 추계학회 보고 ${ }^{12}$ 에서 중증 MAS 환아를 세 척+보충군 15 명과 대조군 14 명을 나누어 치료군에서 투여 24 시 간 이후부터 대조군보다 의미있는 OI감소 $(P<0.05)$ 가 있었고 평 균 인공환기일수(4.9 vs 7.0, $P<0.05)$ 와 산소투여일수 $(9.4$ vs 12.9 , $P<0.01$ ) 및 입원일수(12.4 vs 17.1, $P<0.01$ ) 들도 의미있게 짧았으 며, 기흉과 PPHN 동반 및 사망률도 치료군에서 대조군의 약 반정 도로 낮았으나 환아수가 적어서인지 통계적 차이는 없었다.

이후 Lee 등 ${ }^{38)}$ 이 중증 MAS 환아를 세정요법 7명과 대조군 8명 을 비교하여 세정요법군에서 빠른 OI호전 $(P<0.05)$ 과 짧은 평균 인공환기 시간수( 40.0 vs $68.4, P<0.05)$ 와 입원일수(9.0 vs 12.6 , $P<0.05)$ 가 있었지만, 기흉과 PPHN 빈도는 유사하였고 사망한 환 아는 양군에서 없었다.

Choi 등 ${ }^{39}$ 은 대량 폐출혈 환아 20 명을 $\mathrm{SF}$ 보충군 10 명과 대조군 10 명과 비교하여 투여후 평균 OI는 유사하였고, 의미있게 짧은 평 균 인공환기일수(19.0 vs $35.5, P<0.05)$ 가 있었으며, 심한 만성 폐

Table 1. Summary of Data in Foreign-controlled Studies

\begin{tabular}{|c|c|c|c|c|}
\hline Study & Type of therapy & Age at study & Agent & Favorable outcomes \\
\hline Findlay, et $\mathrm{al}^{25)}$ & bolus & $<6$ hour & Beractant & $\begin{array}{l}\text { Improve oxygenation, Reduce incidence of air leaks and ECMO } \\
\text { requirement, and hospitalization time }\end{array}$ \\
\hline Wiswell, et $\mathrm{al}^{27)}$ & lavage & $<72$ hour & Lucinactant & Rapid decline in oxygenation indexes \\
\hline Chinese study ${ }^{28)}$ & bolus & $<36$ hour & Poractant & Improve oxygenation \\
\hline Segel, et al ${ }^{30)}$ & lavage & $<48$ hour & Lucinactant & Similar effect \\
\hline
\end{tabular}


Table 2. Summary of Data in Korean-controlled Studies

\begin{tabular}{|c|c|c|c|c|}
\hline Study & Type of therapy & Disease & Agent & Favorable outcomes \\
\hline Choi, et al $^{12)}$ & lavage+bolus & severe MAS & Newfacten & $\begin{array}{l}\text { Improve oxygenation, Reduce duration of ventilation and } \\
\text { oxygen supplement, and hospitalization day }\end{array}$ \\
\hline Choi, et al ${ }^{39)}$ & lavage & massive pulmonary hemorrhage & Curosurf & $\begin{array}{l}\text { Reduce duration of ventilation day, Fewer incidence of } \\
\text { BPD or death }\end{array}$ \\
\hline
\end{tabular}

Abbreviation: BPD, bronchopulmonary dysplasia.

질환과 사망 빈도는 $10 \%$ vs $70 \%$ 로 $\mathrm{SF}$ 보충군에서 의미있게 낮았 다 $(P<0.05)$. 이 연구들을 요약하면 Table 2 와 같다. 한가지 특이한 사항은 $\mathrm{MAS}$ 환아들 중 외부 출생아의 빈도가 저자들 ${ }^{12)}$ 에서 $93 \%$, Choi 등 ${ }^{37)}$ 에서 $100 \%$, Lee 등 ${ }^{38)}$ 에서 $60 \%$ 로 전체의 $84.6 \%$ 를 차지하 여 전원전의 분만 병원에서의 적절한 초기 치료가 경과와 예후에 중요할 것으로 생각된다. 메타 분석이 필요한 연구이나 환아수의 부족과 투여 방법과 투여 약제의 다양함 때문에 분석이 어려웠고 향후 통일된 다기관 연구로 더 많은 연구가 필요할 것으로 생각된 다. 이 외에 중이염 환아를 대상으로 한 분무 치료의 국내 보고가 있었지만 여기서는 언급하지 않았다.

\section{결론}

태변은 폐표면 활성제의 강력한 불활성화 시키는 물질로 알려 져 있으며, 근래 폐표면 활성제의 결핍이나 비활성화를 유발하는 태변 흡인 증후군을 포함한 여러 질환들이 호흡 부전을 유발한다. 중증 태변 흡인 증후군에서 폐표면 활성제 치료가 세계적으로 많 이 이용되고 있으며 저자들은 국내외적인 보고들을 고찰해 보고 자 한다. 일반적으로 중증 MAS에서 폐표면 활성제 치료는 폐 산 소화(산소화 지수 혹은 동맥혈-폐포 산소 분압비)를 개선시키며, 산소 투여기간과 입원 기간을 단축시키는 것으로 알려져 있다. 그 러나 사망률과 후유증 개선은 결과가 다양하였다. 국내 연구에 서는 환아들 중에서 외부 출생아가 내부 출생아 보다 약 5 배 많아 서, 일차 분만병원에서의 기도 흡인을 포함한 적절한 관리가 중증 $\mathrm{MAS}$ 경과를 개선시키는데 중요할 것으로 생각된다. 폐표면 활성 제 치료의 효과를 확립하기 위해서는 더 잘 계획된 다기관 무작위 표본 연구가 필요하며, 적절한 투여방법(세정, 보충 혹은 병합)과 용량 및 투여 기간의 설정이 필요하겠다.

\section{REFERENCES}

1) Avery ME, Mead J. Surface properties in relation to atelectasis and hyaline membrane disease. AMA J Dis Child 1959;97:51723.

2) Fujiwara $T$, Maeta $H$, Chida $S$, Morita $T$, Watabe $Y$, Abe $T$. Artificial surfactant therapy in hyaline-membrane disease. Lancet 1980;1:55-9.

3) Auten RL, Notter RH, Kendig JW, Davis JM, Shapiro DL. Surfactant treatment of full-term newborns with respiratory failure. Pediatrics 1991;87:101-7.

4) Blanke JG, Jorch G. Surfactant therapy in severe neonatal respiratory failure-multicenter study-II. Surfactant therapy in 10 newborn infants with meconium aspiration syndrome. Klin Padiatr 1993;205:75-8.

5) Lewis JF, Veldhuizen R. The role of exogenous surfactant in the treatment of acute lung injury. Annu Rev Physiol 2003;65:61342

6) Raju TN, Langenberg P. Pulmonary hemorrhage and exogenous surfactant therapy: a metaanalysis. J Pediatr 1993;123: 603-10.

7) Herting E, Gefeller O, Land M, van Sonderen L, Harms K, Robertson B. Surfactant treatment of neonates with respiratory failure and group B streptococcal infection. Members of the Collaborative European Multicenter Study Group. Pediatrics 2000;106:957-64.

8) Tibby SM, Hatherill M, Wright SM, Wilson P, Postle AD, Murdoch IA. Exogenous surfactant supplementation in infants with respiratory syncytial virus bronchiolitis. Am J Respir Crit Care Med 2000;162:1251-6.

9) Kurashima K, Ogawa H, Ohka T, Fujimura M, Matsuda T, Kobayashi T. A pilot study of surfactant inhalation in the treatment of asthmatic attack. Arerugi 1991;40:160-3.

10) Griese M, Bufler P, Teller J, Reinhardt D. Nebulization of a bovine surfactant in cystic fibrosis: a pilot study. Eur Respir J 1997;10:1989-94.

11) Bos AP, Tibboel D, Hazebroek FW, Molenaar JC, Lachmann B, Gommers D. Surfactant replacement therapy in high-risk congenital diaphragmatic hernia. Lancet 1991;338:1279.

12) Choi WJ, Kim JY, Lee JW, Park WS, Kim CS, Lee SL, et al. The effect of pulmonary surfactant lavage and replacement thera- 
py in meconium aspiration pneumonia neonates. The 53th Annual Fall Meeting of the Korean Pediatric Society; 2003 Oct 24-25; Seoul. Seoul: The Korean Pediatric Society, 2003; 40.

13) Chen CT, Toung TJ, Rogers MC. Effect of intra-alveolar meconium on pulmonary surface tension properties. Crit Care Med 1985;13:233-6.

14) Moses D, Holm BA, Spitale P, Liu MY, Enhorning G. Inhibition of pulmonary surfactant function by meconium. Am J Obstet Gynecol 1991;164:477-81.

15) Bae CW, Takahashi A, Chida S, Sasaki M. Morphology and function of pulmonary surfactant inhibited by meconium. Pediatr Res 1998;44:187-91.

16) Cleary GM, Antunes MJ, Ciesielka DA, Higgins ST, Spitzer AR, Chander A. Exudative lung injury is associated with decreased levels of surfactant proteins in a rat model of meconium aspiration. Pediatrics 1997;100:998-1003.

17) Sun B, Curstedt T, Robertson B. Surfactant inhibition in experimental meconium aspiration syndrome. Acta Paediatr 1993;82:182-9.

18) Dargaville PA, South M, McDougall PN. Surfactant and surfactant inhibitors in meconium aspiration syndrome. J Pediatr 2001;138:113-5.

19) Vidyasagar D, Lukkarinen $H$, Kaapa $P$, Zagariya A. Inflammatory response and apoptosis in newborn lungs after meconium aspiration. Biotechnol Prog 2005;21:192-7.

20) Okazaki K, Kondo M, Kato M, Kakinuma R, Nishida A, Noda $\mathrm{M}$, et al. Serum cytokine and chemokine profiles in neonates with meconium aspiration syndrome. Pediatrics 2008;121: e748-53.

21) de Beaufort AJ, Bakker AC, van Tol MJ, Poorthuis BJ, Schrama AJ, Berger HM. Meconium is a source of pro-inflammatory substances and can induce cytokine production in cultured A549 epithelial cells. Pediatr Res 2003;54:491-5.

22) De Luca D, Minucci A, Zecca E, Piastra M, Pietrini D, Carnielli VP, et al. Bile acids cause secretory phospholipase A2 activity enhancement, revertible by exogenous surfactant administration. Intensive Care Med 2009;35:321-6.

23) Kääpä $P$, Soukha $H$. Phospholipase $A 2$ in meconium-induced lung injury. J Perinatol 2008;28 Suppl 3:S120-2.

24) Khammash H, Perlman M, Wojtulewicz J, Dunn M. Surfactant therapy in full-term neonates with severe respiratory failure. Pediatrics 1993;92:135-9.

25) Findlay RD, Taeusch HW, Walther FJ. Surfactant replacement therapy for meconium aspiration syndrome. Pediatrics 1996; 97:48-52.

26) Lam BC, Yeung CY. Surfactant lavage for meconium aspiration syndrome: a pilot study. Pediatrics 1999;103:1014-8.
27) Wiswell TE, Knight GR, Finer NN, Donn SM, Desai H, Walsh WF, et al. A multicenter, randomized, controlled trial comparing Surfaxin (Lucinactant) lavage with standard care for treatment of meconium aspiration syndrome. Pediatrics 2002; 109:1081-7.

28) Chinese Collaborative Study Group for Neonatal Respiratory Diseases. Treatment of severe meconium aspiration syndrome with porcine surfactant: a multicentre, randomized, controlled trial. Acta Paediatr 2005;94:896-902.

29) Dargaville PA, Copnell B, Mills JF, Haron I, Lee JK, Tingay DG, et al. Randomized controlled trial of lung lavage with dilute surfactant for meconium aspiration syndrome. J Pediatr 2011; 158:383-9.e2.

30) Segal R, Wiswell TE. Phase III randomized study of lucinactant in full term newborn infants with meconium aspiration syndrome. ClinicalTrials.gov.2012 [accessed 2013 Aug 7]. Available from: http://clinicaltrials.gov/show/NCT 00004500.

31) Luo FF, Yang DY, Chen P, Hua ZY. Effect of pulmonary surfactant therapy in neonates with meconium aspiration syndrome: a meta-analysis. Zhongguo Dang Dai Er Ke Za Zhi 2012;14:413-7.

32) Cho YJ, Lee HJ, Lee SL. A case of massive pulmonary hemorrhage treated with pulmonary surfactant replacement. J Korean Soc Neonatol 1999;6:258-62.

33) Shon SM, Lee BY, Kim CS, Lee SL, Kwon TC. The outcome of surfactant replacement therapy in above nearterm neonates with severe pulmonary disease. Korean J Pediatr 2007;50: 1200-5.

34) Choi BY, Kim KM, Yoon JS, Lee JS. A case of acute respiratory distress syndrome treated with surfactant and low dose methylprednisolone. Korean J Pediatr 2006;49:455-9.

35) Park JH, Kim CS, Lee SL. A case of acute respiratory distress syndrome due to maternal blood aspiration. Korean J Perinatol 2009;20:74-7.

36) Park SW, Kim CS, Lee SL, Kwon TC. Clinical findings of severe amniotic fluid aspiration pneumonia and effects of surfactant replacement therapy. Korean J Pediatr 2009;52:429-34.

37) Choi CW, Kim BI, Lee HJ, Joung KE, Shim GH, Lim IS, et al. Clinical characteristics of severe meconium aspiration syndrome. Korean J Pediatr 2008;51:713-21.

38) Lee SM, Kim HM, Jeon JH, Park MS, Park KI, Namgung R, et al. Effect of surfactant lavage in severe meconium aspiration syndrome. Korean J Pediatr 2008;51:367-71.

39) Choi HJ, Sin YH, Kim SM. Exogenous surfactant therapy in neonates with respiratory failure due to pulmonary hemorrhage. Korean J Perinatol 2011; 22:319-28. 